\title{
Interdisciplinary doctoral research networks: enhancers and inhibitors of social capital development
}

\section{Nicola Mountford, Matthew Coleman , Threase Kessie \& Tara Cusack}

To cite this article: Nicola Mountford, Matthew Coleman , Threase Kessie \& Tara Cusack (2020) Interdisciplinary doctoral research networks: enhancers and inhibitors of social capital development, Studies in Higher Education, 45:12, 2558-2573, DOI: 10.1080/03075079.2019.1623768

To link to this article: https://doi.org/10.1080/03075079.2019.1623768

\section{Published online: 07 Jun 2019.}

Submit your article to this journal $\widetilde{ }$

Llll Article views: 514

\section{Q View related articles $₫$}

View Crossmark data ¿

Citing articles: 1 View citing articles $\sqsubset$ 


\title{
Interdisciplinary doctoral research networks: enhancers and inhibitors of social capital development
}

\author{
Nicola Mountford (iD) ${ }^{\mathrm{a} *}$, Matthew Coleman ${ }^{\mathrm{b}}$, Threase Kessie $\mathbb{D}^{\mathrm{c}}$ and Tara Cusack (D) \\ ${ }^{a}$ School of Business, Maynooth University, Maynooth, Ireland; 'brish Pharmaceutical Healthcare Association, Dublin, \\ Ireland; 'The Insight Centre for Data Analytics, University College Dublin, Dublin, Ireland; 'School of Public Health, \\ Physiotherapy, Sports Science, University College Dublin, Dublin, Ireland
}

\begin{abstract}
Interdisciplinary research networks are increasing, with professionals encouraged to undertake research across disciplines to increase innovation, creativity and knowledge. More recently, this interdisciplinary focus is being mirrored by the establishment of interdisciplinary doctoral research networks. But do these networks work? And if so, how and why? We employ social capital theory to (a) understand the lived experiences of students in interdisciplinary doctoral programmes and (b) build programme design theory to support the development of social capital within such programmes. We present the results of 28 semi-structured interviews conducted with doctoral students from three European Union funded interdisciplinary research training networks to understand how they perceive the enhancers, inhibitors and manifestations of social capital within their networks. Key themes revolve around 'extracting value from the interdisciplinary process', 'motivating students throughout the interdisciplinary programme journey', and 'relating to others both within and external to the programme'. We propose a framework for interdisciplinary programme design.
\end{abstract}

\section{KEYWORDS}

Interdisciplinarity; doctoral education; social capital; interdisciplinary; study program; healthcare education and training

\section{Introduction}

Interdisciplinary research is increasing in both quantum and influence (Van Noorden 2015), driven in part by the increasing and urgent need to address contemporary societal challenges. Interdisciplinary collaboration is promoted as a strategy to develop new avenues of scholarly inquiry and generate knowledge that is immediately applicable to the resolution of real-world problems (Wall and Shankar 2008). Funding agencies have increasingly demonstrated preference for interdisciplinary research (Luks and Siebenhüner 2007; Martimianakis and Muzzin 2015). Interdisciplinary research can be a disrupter - driving innovation and increasing creativity while pushing back existing scientific knowledge boundaries: 'there's something in the conversation between multiples that creates maybe new lines of flight, new directions, new inspirations, new energy or new possibilities' (Martimianakis and Muzzin 2015, 1462).

Much of the evidence for the positive aspects of interdisciplinary research is based on empirical studies of interdisciplinarity at the level of the mature, established academic. However, at the doctoral level, where the opportunity to embed interdisciplinary skills and networks may be greater, questions remain unanswered. Such questions include: How do interdisciplinary doctoral networks work in reality? Is it sufficient to form these doctoral student networks and assume they will 'just work'? In this paper, we employ social capital theory within an interdisciplinary context to (a) understand 
the lived experiences of students in interdisciplinary doctoral programmes and (b) build programme design theory that can support the development of social capital within interdisciplinary doctoral research networks. We explore how students undertaking doctoral studies within three European Union funded interdisciplinary research training networks perceive the enhancers, inhibitors and manifestations of social capital within their networks.

Firstly, in the following section, we examine the theory of social capital, the concept of interdisciplinarity, and how these apply in a doctoral student network. We develop operational definitions of both social capital and interdisciplinarity and consider the links between the two concepts. Secondly, we present the findings of a qualitative study and propose a framework within which the interdisciplinary doctoral experience can be understood and potentially be better managed. Finally, we discuss the implications and findings of this work against the backdrop of contemporary literature. The main contribution of this paper is to present a framework for the management of an interdisciplinary doctoral programme. We add to research on interdisciplinarity and fourth level education by describing the particular challenges associated with the recognition and extraction of value within an interdisciplinary PhD network due to the seemingly opposed forces of disciplinary depth and interdisciplinary breadth. Our framework describes how both strong and weak ties are required in such contexts and how these are facilitated by the development of a lingua franca or a shared language across the disciplines involved. We also identify societal motivation as particularly important in combatting the uncertainty inherent in such confusing and relatively unstructured doctoral studies environments.

\section{The role of social capital in interdisciplinary doctoral research networks}

Interdisciplinarity has been defined as 'the interaction among two or more different disciplines' (Berger 1972, 25) and ranges from 'simple communication of ideas to the mutual integration of organising concepts, methodology, procedures, epistemology, terminology, data, and organisation of research and education in a fairly large field' (Berger 1972, 25). An interdisciplinary group, according to (Berger 1972, 25-26), is one that includes those trained in different fields of knowledge (disciplines) working together on a common problem in a way that requires continuous communication across disciplines. This constant and integrative level of communication inherent in the interdisciplinary concept (Hattery 1986) forms a connection or bridge between disciplines that facilitates the resolution of 'actual' problems (Brewer 1999) through the creation of 'a kind of meta-knowledge' (Karlqvist 1999, 379). 'Interdisciplinarity is a means of solving problems and answering questions that cannot be satisfactorily addressed using single methods or approaches' (Klein $1990,196)$. Therefore, for interdisciplinarity to be effective, communication is a vital component.

Interdisciplinarity often flounders on the very rocks on which it must build - those disciplinary foundations that offer the initial depth of expertise that is leveraged in the interdisciplinary effort. These blockages can be structural, epistemological, practical/professional, and sociological in nature. Examples of structural blockages include the formal barriers between disciplines created by the institutionalised university structure (Braddock, Fien, and Rickson 1994); the difficulty in publishing interdisciplinary work due to the inherently disciplinary nature of the peer review process (Fry 2001), and the lack of value placed upon interdisciplinary pursuits in academic hiring and promotional processes (Brewer 1999; Fry 2001). Epistemological differences include the nature of knowledge and means of acquiring such knowledge (Bradbeer 1999; Brewer 1999). For example, while qualitative work is welcomed and valued in particular spheres, other disciplines may accord a higher level of respect to quantitative work (Fry 2001). This adds to already present personal challenges in winning the respect and trust of interdisciplinary colleagues (Brewer 1999). Interdisciplinary education has flourished in particular sectors including health (Arenson et al. 2014) and engineering (Ishida et al. 2017). Interdisciplinary engagement is frequently achieved through teaching and learning methods such as Problem-Based Learning (Stentoft 2017) or Project Based Learning (Stozhko et al. 2015). However, Martimianakis and Muzzin's (2015) participant accounts show that 'orienting one's academic work around interdisciplinarity requires considerable 'managing' of one's career, 
including negotiating new conceptual spaces and overcoming structural barriers' (Martimianakis and Muzzin 2015, 1466). At the micro level, the sociological process of communicating across disciplines can also be frustrated by the use of different, often specialised 'languages' employed by sometimes insular disciplinary communities (Nagy and Townsend 2012). Given that interdisciplinarity seeks to 'design, implement, and bring to a consensus the results of a systematic investigation' of a particular problem (Bruhn 2000, 58); and taking into account the need for constant inter-communication discussed above, overcoming this language barrier can be one of the most crucial challenges for an interdisciplinary team.

Social capital theory offers a theoretical approach to explain how such individuals, groups, and organisations manage relationships and access knowledge resources (Filieri et al. 2014). Pierre Bourdieu defined social capital as 'the aggregate of the actual or potential resources which are linked to possession of a durable network of more or less institutionalised relationship of mutual acquaintance or recognition' (Bourdieu 1985, 248). Putnam $(1993,167)$ added 'features of social organization, such as trust, norms, and networks, that can improve the efficiency of society by facilitating coordinated actions', and 'connections among individuals - social networks and the norms of reciprocity and trustworthiness that arise from them'. Social networks have value because they allow access to both Bourdieu's resources and Putnam's social attributes (Kadushin 2012). The fundamental and consistent definition of social capital focuses on resources embedded in social relations and social networks (Lin and Erickson 2008). The cognitive dimension of social capital concerns shared interpretations and systems of meaning and shared language and codes, attitudes and beliefs that provide the foundation for communication (Gooderham 2007; Krishna and Uphoff 2002; Uphoff 2000). The relational dimension of social capital refers to such facets of personal relationships as trust, obligations, respect and even friendship, which together increase the motivation to engage in knowledge exchange and teamwork (Gooderham 2007). Social capital has been reported to increase the efficiency of knowledge transfer by encouraging cooperative behaviour (Nahapiet and Ghoshal 2000).

Enns, Malinick, and Matthews (2008) similarly found that the majority of ties to potential resourcerich positions were weak ties located inside the community. Strong ties are those that are intense, frequent and multiple in terms of relationship types, while weak ties form links between groups and are frequently an important resource in terms of social capital (Granovetter 1973). Researchers who have interdisciplinary collaborations have been shown to be more productive, suggesting that the following are key to social capital: numerous ties, a central position, partners from different areas of knowledge, and being part of a network (Gonzalez-Brambila 2014). Indeed, social ties to a wide variety of skills, knowledge and perspectives appear to act as a social resource that offers a variety of benefits (Magee 2008). Indeed, Pilbeam, Lloyd-Jones, and Denyer (2013) found that doctoral students benefit from the social capital available within their particular network and especially value the support, validation of personal progress, problem-solving and personal development. Their study of doctoral students reported facilitators to network formation that included shared experience, knowing that others were struggling with the same experience, and the notion of a common unique purpose (striving to attain a doctorate). Students engaged in an interdisciplinary doctoral programme indicated, however, that there was a lack of peer support, institutional support, and lack of structure (Gardner 2011).

So we know that social capital is exceptionally important to doctoral student networks (Pilbeam, Lloyd-Jones, and Denyer 2013), that social capital requires cognitive and relational elements (Gooderham 2007; Krishna and Uphoff 2002; Uphoff 2000) and that interdisciplinary research often operates within structures, epistemologies and professional practices that are antithetical to the development of such cognitive and relational elements (Bradbeer 1999; Braddock, Fien, and Rickson 1994; Brewer 1999; Fry 2001). What is not clear from the literature, however, is whether and how social capital can be developed and leveraged by individuals within the network despite interdisciplinary differences. We go on to explore this setting with a view to developing a framework that may answer this question. 


\section{Context}

In 2014 and 2015 the European Union awarded funding ${ }^{1}$ to 3 pan-European consortia to develop and deliver structured doctoral training in the area of Connected Health. Connected Health refers to 'a conceptual model for health management where devices, services or interventions are designed around the patient's needs, and health-related data is shared, in such a way that the patient can receive care in the most proactive and efficient manner possible' (Caulfield and Donnelly 2013). Connected Health is impacted by multiple drivers including technology, healthcare, business and policy (Mountford et al. 2017) and therefore requires an interdisciplinary research approach. CHESS (Connected Health Early Stage Researcher Support System network ${ }^{2}$ ) has 15 doctoral students drawn from a wide variety of disciplines (doctors, physiotherapists, computer scientists, electrical engineers, business). While each student works on a discreet doctoral research project, as a whole these projects hope to increase and expedite adoption of Connected Health models. CATCH (Cancer - Activating Technology for Connected Health ${ }^{3}$ ) is composed of eight doctoral students from a variety of disciplines (medicine, computer science, physiotherapy) who will bridge the gap between cancer survivors' depleted physical and emotional state, and their ability to return to a fully functional societal role through technology supported physical exercise (Mountford et al. 2018). TEAM (Technology Enabled Mental Health ${ }^{4}$ ) focuses on key challenges in youth mental health: delivering new technologies to support rapid, large-scale, and early assessment, prevention and treatment and comprises of 15 doctoral students with qualifications in psychology, computer science, interaction design, health sciences, and law. Due to the requirements of the funding programme, all students were required to have been resident outside the country in which they undertook the PhD programme for more than 12 months in the preceding 3 years. For this reason, many of the students were working outside their home country. Some travelled from other European countries, others from outside the EU, with some returning to their home country after a period living abroad.

In each programme a cohort of PhD students, based in a number of universities and non-academic partner organisations work on discrete doctoral research theses that together aim to address larger societal challenges. Where students are based in non-academic organisations they are registered for their PhD studies within one of the academic partners within the consortium. All students across the programme are supervised by a primary academic supervisor for the purpose of their PhD studies. They are also supported by a doctoral studies panel which has a minimum of one additional academic supervisor and one non-academic supervisor. While the students receive no formal training in interdisciplinarity, they are expected to interact and engage in an interdisciplinary way. Each of the programmes incorporates specific tasks beyond the doctoral thesis that must be completed as an interdisciplinary group. For example, the CHESS programme includes the collaborative development of a Connected Health Index that would allow Connected Health progress to be tracked based on various multi-disciplinary measures - ICT infrastructure, business models, integrated care models, etc. Students meet each other face-to-face at least once per year at a week-long summer school and maintain ongoing communication through a formal web-based forum as well as informal social media groups such as Facebook and Whatsapp. Each student undertakes an 'intersectoral secondment' of at least 3 months (maximum 18 months) duration during their programme. This means that a student hosted in industry will spend time in an academic member of the consortium, while a university-based student will spend time in either an industry or healthcare setting. While not true of all students in the programmes, many of them will spend this secondment time in a different country offering additional international exposure.

Three of the authors had varied involvement in the development and delivery of these programmes. NM was involved in the writing of the proposal documents that secured the funding for the above programmes; TK was the administrative manager for the CATCH programme; and TC supervised one of the PhD students on the CHESS programme. MC was not involved with any of the programmes and conducted all of the qualitative interviews with the students. He was hired specifically to conduct this piece of research and had no previous involvement with the students 
or their supervisors. MC anonymised the interview data and withheld this information from the other three authors given their ongoing involvement with the programmes. At no point did TC see or review her own PhD students' interview transcripts as it was deemed likely that her level of knowledge would make the student identifiable from the transcript. The funding for this research on the student experience was provided by a data analytics research centre (Insightcentre.org) and was completely unrelated to the funding that underpinned the programmes provided by the European Union. All these facts and measures were communicated to the students involved in an effort to address any perceived or actual power relations. The project was reviewed and granted an ethical exemption by the research ethics committee of University College Dublin. All interviewees gave informed consent for the interviews.

\section{Methods}

Twenty-eight one-to-one semi-structured interviews were undertaken with twenty-seven doctoral students (one was interviewed twice) from across the three programmes (either face-to-face or by Skype) with a view to understanding their lived experience on their corresponding interdisciplinary doctoral programme. All informants demonstrated 'thorough enculturation' and 'current involvement' in an interdisciplinary doctoral programme (Spradley 2016, 46). All interviews were undertaken by one author $(\mathrm{MC})$, were audio recorded and were transcribed verbatim with a view to preserving the true voice of each informant. The interviews averaged 48 minutes and 14 seconds (48'14') in length with the shortest interview lasting $36^{\prime} 22^{\prime \prime}$ and the longest $59^{\prime} 05^{\prime \prime}$. An interview topic guide encouraged the interviewer to cover topics such as 'the student's background before the programme', 'expectations coming into the programme', 'experience of the programme', 'skills development', and 'future plans'. A summary report was generated after each interview as a means of recording early observations and refining further questioning, for example following saturation of participant response. For each of the doctoral students, the interviews were undertaken at different points in time over the first two years of their doctoral studies (for further details, see Table 1). The CHESS students had for the most part been in post for longer than those in the TEAM and CATCH programmes owing to the fact that it was funded one year previously. Table 1 provides an overview of the interviewed students' disciplinary backgrounds on entering the programme. Thematic analysis was undertaken using the method suggested by Braun and Clarke (2006). This method of thematic analysis involves identifying, analysing, and reporting patterns (themes)

Table 1. An overview of the students interviewed.

\begin{tabular}{|c|c|c|c|c|c|}
\hline Student & Disciplinary background & $\begin{array}{l}\text { Stage of PhD } \\
\text { studies }\end{array}$ & Student & Disciplinary background & $\begin{array}{l}\text { Stage of PhD } \\
\text { studies }\end{array}$ \\
\hline 001 & Physiotherapy & $18-24$ months & 015 & Psychology & $3-6$ months \\
\hline 002 & $\begin{array}{l}\text { Computer science/human } \\
\text { computer interaction }\end{array}$ & $0-3$ months & 016 & Physiotherapy & $12-18$ months \\
\hline 003 & Medical doctor & 12-18 months & 017 & Business & $0-3$ months \\
\hline 004 & Sport \& exercise science & $6-12$ months & 018 & $\begin{array}{l}\text { Computer science/human } \\
\text { computer interaction }\end{array}$ & $6-12$ months \\
\hline 005 & IT & $12-18$ months & 019 & IT & $12-18$ months \\
\hline 006 & Psychology (2 interviews) & $\begin{array}{l}\text { Pre-PhD/0-3 } \\
\text { months }\end{array}$ & 020 & IT & $6-12$ months \\
\hline 007 & Law & $0-3$ months & 021 & IT & $3-6$ months \\
\hline 008 & Physiotherapy & 6-12 months & 022 & Biomedical engineering & $12-18$ months \\
\hline 009 & $\begin{array}{l}\text { Computer science/human } \\
\text { computer Interaction }\end{array}$ & 18-24 months & 023 & Biomedical engineering & 18-24 months \\
\hline 010 & $\begin{array}{l}\text { Computer science/human } \\
\text { computer interaction }\end{array}$ & $3-6$ months & 024 & Business & $18-24$ months \\
\hline 011 & Medical doctor & $18-24$ months & 025 & Business & 18-24 months \\
\hline 012 & Sport \& exercise science & $6-12$ months & 026 & Biomedical engineering & $12-18$ months \\
\hline 013 & Psychology & $6-12$ months & 027 & Business & $6-12$ months \\
\hline 014 & Psychology & $3-6$ months & & & \\
\hline
\end{tabular}




\begin{tabular}{|c|c|c|c|}
\hline Sample Quotes & First-order themes & $\begin{array}{l}\text { First-level } \\
\text { theoretical }\end{array}$ & $\begin{array}{l}\text { Second-level } \\
\text { aggregate }\end{array}$ \\
\hline $\begin{array}{l}\text { "I think what's really nice is that between all the PhD's we're kind of in a similar } \\
\text { situation in trying to get to grips with where you're going to fit in as part of the } \\
\text { wider program and equally already though I've benefited from justvery either } \\
\text { specific chats or general chats with the different members." (ESRO14) }\end{array}$ & $\begin{array}{l}\text { Sharing experiences - both } \\
\text { personal and professional }\end{array}$ & categories & categories \\
\hline $\begin{array}{l}\text { "...everybody is thinking like oh the user are the children no the user is the } \\
\text { psychologist or the therapist...the user is.....well there's different words that } \\
\text { have different meanings for everybody in the field" (ESROO2) }\end{array}$ & $\begin{array}{l}\text { Words and meanings change } \\
\text { from discipline to discipline }\end{array}$ & Language & $\begin{array}{l}\text { Relating in an } \\
\text { inter- } \\
\text { disciplinary }\end{array}$ \\
\hline $\begin{array}{l}\text { "I have better opportunities on collaborating with people from Sweden, going to } \\
\text { this ENJECT school in London, and probably meet the people from MIT.". } \\
\text { (ESROO9) }\end{array}$ & $\begin{array}{l}\text { Opens up networks beyond } \\
\text { the PhD programme }\end{array}$ & Networks & context \\
\hline $\begin{array}{l}\text { "you have to learn how to...how to say the words...the things that you want to } \\
\text { say...to explain them and make yourself understood and you also have to } \\
\text { understand their point of view." (ESROOB) }\end{array}$ & $\begin{array}{l}\text { Inter-disciplinarity takes time, } \\
\text { and the right attitude }\end{array}$ & Expectations & \\
\hline $\begin{array}{l}\text { "So I've got guys from all over... obviously X is kind of the business side of it and } \\
\text { the engineering side of it with the stimulators... Y is the hospital side of itso, I'm } \\
\text { doing my ethics now so she is great to have on hand any questions regarding } \\
\text { ethics" (ESRO04) }\end{array}$ & $\begin{array}{l}\text { Others as encyclopaedias, } \\
\text { borrowing perspectives to } \\
\text { avoid blinkered thinking } \\
\end{array}$ & Perceptions & $\begin{array}{l}\text { value from } \\
\text { the inter- } \\
\text { disciplinary }\end{array}$ \\
\hline $\begin{array}{l}\text { "But they may not be able to share good knowledge...it's not actually very } \\
\text { relevant. So it's better that each of us work on our own thesis and whenever we } \\
\text { feel that we need to see each other we schedule [it]" (ESRO21) }\end{array}$ & $\begin{array}{l}\text { There's a time and a place: for } \\
\text { inter-disciplinary working and } \\
\text { within discipline working }\end{array}$ & Capacity & evperians \\
\hline $\begin{array}{l}\text { "I wanted a change and this PhD gave me the opportunity to do that so I'm not } \\
\text { really young so I'm close to } 40 \text { and to change bus iness context if I want to start in } \\
\text { another type of business is difficult but with this PhD first I have a salary, second I } \\
\text { wanted to start working in digital health" (ESRO27). }\end{array}$ & $\begin{array}{l}\text { Multiple internal drivers - } \\
\text { personal and professional, } \\
\text { security and challenge }\end{array}$ & Intrinsic Drivers & Motivating in \\
\hline $\begin{array}{l}\text { "To me research isn't just... its not something you do just to get a paper out. its } \\
\text { something you do to make a difference to actually change the way we practice } \\
\text { and we do things, and if you're not intending on chang ing something then there's } \\
\text { no point in doing it" (ESROO1). }\end{array}$ & $\begin{array}{l}\text { Seeking real change in the } \\
\text { world }\end{array}$ & Extrinsic Drivers & $\begin{array}{l}\text { an inter- } \\
\text { disciplinary } \\
\text { environment }\end{array}$ \\
\hline $\begin{array}{l}\text { "you don't know if it going to work or not and moving to a different country with } \\
\text { a different language..the environment and meeting new people and you know } \\
\text { struggling with the paperwork from you know for the revenue and getting a PPS } \\
\text { number and all those kinda things.. in the beginning was really hard for me.." }\end{array}$ & $\begin{array}{l}\text { Uncertainty on multiple fronts } \\
\text { at once }\end{array}$ & Uncertainty & \\
\hline
\end{tabular}

Figure 1. The coding process.

within the data and minimally organising and describing the data set in detail. However, it also often goes further than this and interprets various aspects of the research topic (Boyatzis 1998).

All authors familiarised themselves individually with the complete data set through an initial reading, noting early ideas. A random sample of 10 interviews were then selected and this sample was read in detail by all authors. Each author developed their own ideas regarding the themes which were emerging from the data. Following several detailed discussions an agreed coding framework was developed. These codes were subsequently used to systematically identify interesting features of the data across the entire data set, and to collate data relevant to each code. The authors then discussed the coding structure and areas of agreement and disagreement. Disagreements were resolved through discussion. A redrafted coding structure was developed and all transcripts were recoded, each transcript being coded by a minimum of two authors. Codes were collated into potential themes using an inductive 'bottom up' (Blair 2015) approach and all data relevant to each potential theme was identified. Discussion took place between all authors regarding how the themes worked in relation to the coded extracts and the entire data set and a thematic map was generated (see Figure 1 for more detail). The focus of this study was on examining the implication of disciplinary background in relation to the experience of being part of a PhD network. While some students did discuss their experience of cultural differences and in some cases the practicalities of moving to a new country, particularly if they had children, these differences were not considered to be sufficient to warrant subgroup analyses.

\section{Findings: the lived experience of the interdisciplinary doctoral student}

\section{Relating in an interdisciplinary context}

The doctoral students interviewed placed much emphasis on community, experiencing it as a crucial resource, supporting them through the PhD journey. They identified challenges inherent to being part of an interdisciplinary community including the necessity of developing a common language 
to bridge the interdisciplinary divide. As both $\mathrm{PhD}$ students and supervisors were drawn from diverse professional backgrounds and contexts, communication was recognised as vital to community development. Finally, doctoral students clearly valued the networking and collaboration opportunities afforded to them both within and outside the programme.

\section{Community}

The doctoral students placed both personal and professional value on a supportive community where students are in

a similar situation in trying to get to grips with where you're going to fit in as part of the wider program ...

(Student 014)

This included both

specific chats or general chats with the different members. (Student 014)

Being part of the training network community enabled PhD students to evaluate their own progress:

It's really important especially to have PhDs that are a little bit further than you so you can see that the process that you are following, it's normal ... (Student 006)

This community engagement allowed students to come together to 'talk and share ideas and opinions' (Student 007). Personal and professional support manifested as a natural, unintended consequence of involvement in the network. As one student said of their interdisciplinary colleagues:

it helps you frame a problem differently and then suddenly you get a new perspective and that you wouldn't get if you were doing all alone. (Student 014)

\section{Language}

Being part of an interdisciplinary network necessitated an additional level of learning. Developing a common shared language was important so students could build their knowledge and create a new understanding for themselves, particularly considering the diversity of professions with professionspecific terminology:

you have to learn how to ... how to say the words ... the things that you want to say ... to explain them and make yourself understood and you also have to understand their point of view. (Student 003)

when you are lawyer and you are confronting with an engineer you have a different language, different meaning and so that's fascinating but that could be a boundary. (Student 004)

Indeed, students found that different words meant different things depending on their professional background:

... everybody is thinking like oh the user are the children no the user is the psychologist or the therapist .... the user is ... well there's different words that have different meanings for everybody in the field. (Student 002)

\section{Networks}

PhD students valued the opportunity to build new networks (and access existing networks) as an investment in their future. A number of students referred to a parallel European network in Connected Health:

... because we had like the same experience, similar experience, it could be a support network. It depends on the relationship we develop. Maybe some of them could be good friends, a supportive network to get advice later on. (Student 010)

Network nowadays is very important. If you want to, um, move on with your professional career, you definitely have to have ... to know people. And I, mean, it's not only in academia, it's also in industry, everywhere. (Student 020) 


\section{Extracting value from the interdisciplinary experience}

The doctoral students outlined their initial expectations and discussed how these had translated into the reality of the programme. They articulated different perceptions of value - some students focused on the ability to access knowledge that they would otherwise struggle with, seeing their colleagues from another discipline as disciplinary encyclopaedias, whereas others saw value in the different perspectives that such colleagues might offer on the same problem or challenge. Finally, students outlined the challenges of meeting both disciplinary and interdisciplinary objectives within the timeframes available to them.

\section{Expectations}

Intuitively, before coming onto the programme the doctoral students understood that there would be people from backgrounds other than their own - but they nevertheless expressed surprise at the reality of the experience suggesting a lack of up-front information as to the nature of interdisciplinary work:

I had no idea that it was going to be like this ... that CHESS was going to be a big group like this and with all the supervisors and you know all the collaborations that we have with different industries and other academies and I couldn't imagine that insight was like this no idea ... I had no idea ... (Student 003)

Interdisciplinary activities take extra time, but this was not clear to most of the students in advance of starting their programme:

... it's more delayed than everybody thought ... most of all what the supervisors thought ... and it's taking longer than what people thought... (Student 003)

Managing students' expectations of the interdisciplinary process might address some of this potential conflict or misunderstanding. Indeed this could help students appreciate the benefits that accrue from what can be a difficult process. An example of such a misunderstanding occurred during a conversation between two students on CHESS who were both from different backgrounds. A student on the programme with an IT background suggested that doctors were the only ones permitted to kill. Student 003, who had a background as a medical doctor, responded to their comment as follows:

... it's like ok ... relax ... because he has totally no idea ... so you have to explain properly how it is and what it does mean ... so sometimes it's a bit hard. (Student 003)

\section{Perceptions as to value}

The doctoral students who saw value accruing from the interdisciplinary experience tended to speak of such value from two complementary angles. The first saw the interdisciplinary colleague as a disciplinary encyclopaedia that could shortcut their need to wade through large amounts of literature to answer questions that arose outside their own discipline. There was an understanding that this was a give and take process, one of lending and learning (Student 024):

$\ldots \mathrm{X}$ is kind of the business side of it and the engineering side of it with the stimulators ... $\mathrm{Y}$ is the hospital side of it so, I'm doing my ethics now so she is great to have on hand any questions regarding ethics. Z knows pretty much everything to do with stimulation and then W, she's really good to have cause she's kind of a level head on the academic side of it. (Student 004)

A second view of value positions interdisciplinary as an antidote to potential blinkered perspectives:

If you're such an expert in your topic you don't realise that other experts are doing it in a different way and don't think if how you could do it in a different way. (Student 010)

each of us has a different point of view, different ideas, but you have to find a way of doing something that is going to be worth it for the final user but you have to find your common path in that. (Student 003) 
One student summarised the end result of this access to multiple perspectives through the interdisciplinary doctoral programme, describing how, for them, it has

pushed the multidisciplinary bubble boundaries of research. (Student 005)

The value of the interdisciplinary interactions may, however, be somewhat intangible. Reflecting on their first 6 months in the programme, Student 014 described how s/he had learned a lot because of this variety of backgrounds, but that

there isn't necessarily a lot of tangible evidence but there is a lot of say reflective experience in development in that sense, although it's just not tangible. (Student 014)

\section{Capacity}

Bridging interdisciplinary boundaries requires time and effort. We have already discussed the language barriers that must be overcome as well as the unexpected messiness of interdisciplinary working and the time it takes to understand different perspectives on the same issue. When a student attends a conference of another discipline, they often fail to find value in it. In a similar vein, students have had some poor experiences where presenters have presented as if to an audience comprised of their own discipline, rather than a mix of multiple disciplines:

if you're sitting and talking for three hours about some complex data mining or something ... you've lost me ... sorry. (Student 001)

Students recognised a need to maintain a disciplinary network alongside their interdisciplinary network. This 'home' network can offer advice as to appropriate literature and in-depth advice with theory. Students suggested that it was only if they needed something outside their field, for example, access to a particular technology company, or advice on ethical issues, that they tapped into the interdisciplinary network.

But they may not be able to share good knowledge ... it's not actually very relevant. So it's better that each of us work on our own thesis and whenever we feel that we need to see each other we schedule [it]. (Student 021)

\section{Motivating in an interdisciplinary environment}

The diverse personal motivators across the interviews offer an insight into the rationale when deciding to undertake the personal and academic commitment that the interdisciplinary training network requires. Motivation to engage is key to the development of social capital (Gooderham 2007) and our doctoral students speak of both personal and societal motivators. We refer to 'personal motivators' as those that are linked to the students own gains: career, skills, networks, etc. We consider 'societal motivators' to be those linked to seeing improvement in others' lives as a result of the students' actions: either individual others, or society as a whole. We find, however, that the uncertainty inherent in a programme of interdisciplinary doctoral studies can endanger such motivation if not managed or where students have insufficient coping mechanisms.

\section{Personal motivators}

Some joined these interdisciplinary training networks primarily to obtain a PhD degree:

My focus for this whole of this is to achieve a PhD. (Student 001)

The PhD for some was, however, a means to another end - a change in career or a different way of life while others felt that to advance in the field of connected health a PhD was necessary. While some students wished to change their career, others simply wanted something to challenge them or tackle the boredom they felt. A trained physiotherapist, Student 001 had become 
a bit bored of clinical physiotherapy [and] had a desire to branch out and learn new things. (Student 001)

Student 012 wanted another way of investigating their passion - 'physical activity and technology' (Student 012), motivating their move to become involved in research. Therefore, personal and rational factors are intertwined and deeply connected in the decision-making process. Some students expected their interdisciplinary experience to make them unique in their exposure to multiple disciplines and therefore more employable on completion:

One of the things that kind of drew me to this project ... it was the fact it was across three different sectors like industry, academia and clinical ... I think that's really good for me in terms of kind of professional development. (Student 004)

Interdisciplinarity was seen by students as better reflecting 'the real world' as opposed to the more siloed university environment:

you need to be able to link in with people of other professions, to empathise with them, to understand their position, what their priorities are and to kind of see how they view you as well. (Student 008)

\section{Uncertainties}

While a level of uncertainty will always be present in a $\mathrm{PhD}$, this is increased in an interdisciplinary network. Doctoral students in these programmes were working outside their home country, in an interdisciplinary context, while also undertaking an intersectoral secondment:

you don't know if it's going to work or not and moving to a different country with a different language ... the environment and meeting new people and you know struggling with the paperwork. (Student 003)

The mechanics of collaboration and interaction appeared to hold a level of uncertainty for students who, even a year or more into their programme found it

... still quite unclear how we could support each other. (Student 010)

Some of the students have found ways of managing the uncertainty. Student 014 describes her concern over the uncertainty/ambiguity of her planned secondment:

I think when I first started I was very worried about that but I went to visit them when I was in Seville and I've met with [host name redacted] since so I have a better idea of how the business works and what their expectations are because I spoke to them about it kind of generally speaking. (Student 014)

\section{Societal motivators}

A desire to make a difference features strongly throughout the interviews - students were conscious that research outputs were not only necessary for the advancement of their career, but to make a real difference:

To me research isn't just ... it's not something you do just to get a paper out. It's something you do to make a difference to actually change the way we practice and we do things, and if you're not intending on changing something then there's no point in doing it. (Student 001)

I don't just want to do a research and get a certificate of PhD. (Student 027)

This desire to make the research relevant can also be seen in the approach students took to conducting research. They

want[ed] to find a company to work with which has a similar outlook. (Student 024)

to them in terms of their contribution to insurance and eHealth. This was also reflected in a desire for synergy and feeling part of something bigger:

A lot of people, people in our group are asking the important questions of this time and it's all contributing to one bigger picture. (Student 005) 


\section{Discussion: implications for the design of interdisciplinary doctoral programmes}

At the outset of this paper we explained that while the case has been made for interdisciplinarity, how it might work in reality at a doctoral programme level is lacking an operational level of detail. Theoretically, while we know that developing social capital is key for doctoral students (Pilbeam, Lloyd-Jones, and Denyer 2013), we also know that the cognitive and relational elements (Gooderham 2007; Krishna and Uphoff 2002; Uphoff 2000) required for that to happen are that much more difficult to develop and maintain within an interdisciplinary research environment (Bradbeer 1999; Braddock, Fien, and Rickson 1994; Brewer 1999; Fry 2001). Based on the findings articulated previously, we propose a framework for the design of interdisciplinary doctoral networks that facilitates students to develop and leverage social capital, securing the cognitive, structural, and relational elements necessary to facilitate this process (see Figure 2 below). As (Demharter et al. 2017, 1) identified 'an interdisciplinary $\mathrm{PhD}$ is a great chance for students to pursue truly novel research, a range of different career paths, and a stimulating intellectual life. However, these benefits are often accompanied by additional academic and logistical challenges'. We suggest that designing a PhD educational programme with this framework in mind could assist in alleviating some of the additional challenges experienced by PhD students.

Our framework uses the lived experience of the 28 doctoral student interviewees to capture the essence of how social capital is developed and employed within their interdisciplinary networks. In the first instance 'the flow of information' (Lin 1999) is facilitated through the establishment of social ties that enable individuals within the network to relate, but these ties need to be of a strength that allows students to realise informational, resource and sponsorship benefits (Seibert, Kraimer, and Liden 2001). Secondly the students must develop the ability to recognise those informational, resource and sponsorship opportunities when they see them, and have the capacity to absorb them along those strong ties to extract value from the network through their increasing interdisciplinary social credentials. Finally, students must be willing to engage with other disciplines - the motivation to make and leverage these interdisciplinary ties cannot be taken for granted. All these elements serve to reinforce identity and increase professional recognition. Indeed 'growing evidence suggests that network diversity is a key indicator of an individual's stock of social capital' (Magee 2008, 326).

\section{The number and strength of ties (relating)}

While individuals are more likely to send resources along strong ties (Granovetter 1973), weak ties are 'indispensable to individuals' opportunities and to their integration into communities' (Granovetter 1973, 1378) broadening reach, extending networks and accessing social resources (Enns, Malinick, and Matthews 2008). Our doctoral students clearly articulated strong programme-based community ties offering valuable personal and professional support, but also felt empowered to develop additional weaker ties with other groups. Establishing both strong and weak ties offered the opportunity to build and develop the resources available to them. It has been identified that 'ties positively affect future productivity, so that it could be expected that the higher the number of colleagues, the higher the future productivity' (Gonzalez-Brambila $2014,1616)$. Closed networks tend to be more productive than open networks due to the fact that researchers within the network are connected to the majority of other researchers within the network (Gonzalez-Brambila 2014). Gonzalez-Brambila's (2014) work suggests that 'what matters in social capital is having many ties, being in a central position, having partners from different areas of knowledge, and being part of a non-dense network' (1622-1623). In many cases developing strong ties within the $\mathrm{PhD}$ consortium and weaker ties with tangential networks enabled the doctoral students to understand that they can be centrally important within strong tie situations (i.e. their own PhD network) while also building an understand of how weaker ties can also be important. 


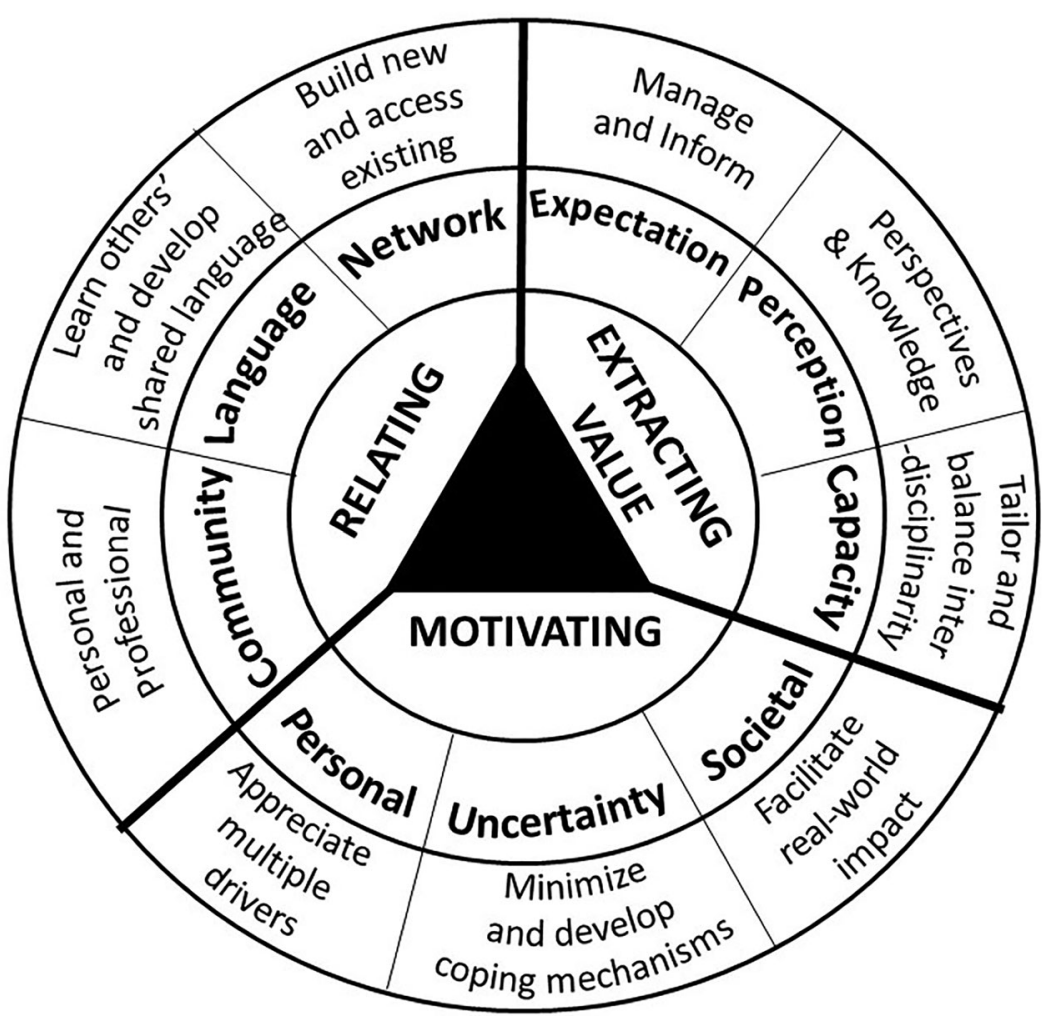

Figure 2. A framework for maximising social capital development in an interdisciplinary fourth level programme.

Language and communication are crucial elements for building social ties. Students saw the development of a common and mutually understood language as essential to tap into the links within and outside their network. A note of caution should be added that due to the international nature of the students involved in this programme, many were operating in their second or third language, therefore, adding a potential secondary impediment to their ability to communicate across boundaries. Being able to communicate and connect with individuals within this diverse interdisciplinary group was the bedrock upon which strong ties were established and the foundation for leveraging social capital. Building the skills required to relate to colleagues within and across disciplines and sectors is a key component of contemporary doctoral education. In addition, developing a shared understanding of the role played by each discipline within the network is a central tenet of successful interdisciplinary work. Both involve developing mutual trust and understanding of the differing professional perspectives within the network. However, it is evident that additional time and commitment are required to develop common language and understanding, and this may in fact have slowed the pace at which individuals could access resources within their network. However, we can only speculate at this stage that the additional time invested in developing and growing both strong and weak ties will reap rewards in terms of the social capital that the doctoral students will yield in their future careers as a result of their participation.

\section{The ability to recognise and stream value along those ties (extracting value)}

The premise of social capital is that investment in social relations will deliver expected returns (Lin 1999). This investment extends beyond simply forging a relationship. It also requires the investor to know how, when and what to ask for in terms of the available resources within that relationship. 
The interdisciplinary PhD network offers students an opportunity to practice this art in a safe and supported environment before having to put it into practice in the real world. A business student begins to understand firstly, the nature of the value that a computer scientist, doctor, or engineer can add; secondly the language and approach that is best calculated to cause their interdisciplinary colleague to release those resources along the social tie; and thirdly, when such resources might be of most value, and might be most easily drawn down. Having learned these skills and having had the opportunity to practice them we anticipate they will have the ability to build stronger ties in their interdisciplinary future - be that in practice or the academy. This know-how, regarding access to resources will allow students to capitalise on their connectedness in the future - enhancing their research productivity, improving quality, and increasing the novelty and innovation of their research projects. This must be balanced, however, with a disciplinary experience and embeddedness that facilitates similar relationships, know-how and practical experience within their discipline. Ultimately they are likely to be more reliant on their disciplinary home turf (particularly if they remain in academia), reflecting the structural, epistemological, practical/professional, and sociological constraints discussed in the early sections of this paper (Bradbeer 1999; Braddock, Fien, and Rickson 1994; Brewer 1999; Fry 2001). Thus, intra-disciplinary ties, access to resources and, in short, intra-disciplinary social capital are also vital. Interdisciplinary PhD programmes must, therefore, invest both time and effort in supporting their students in learning how to develop and maintain a foot in both inter- and intra-disciplinary social camps. This includes provision of the skills, experience and role models necessary to negotiate the new conceptual spaces that they wish to step into while overcoming the structural barriers (Martimianakis and Muzzin 2015).

Our research shows that expectation plays a role in students' ability to extract value from the interdisciplinary experience. Although the direction of causation is uncertain, there is a definite correlation between those whose expectations are met or exceeded, and those who feel that they have benefited from the interdisciplinary experience. Expectation fulfilment is linked to student satisfaction with the level of support available and their realisation of the potential for collaboration to resolve 'actual' problems (Brewer 1999). Where the reality is a disappointment vis-à-vis student expectations it is correlated with the unstructured nature of secondment and the lack of early opportunities to meet other students, supervisors, and secondment hosts. This suggests a need to manage student expectations and inform them as to the challenges and benefits of an interdisciplinary approach to $\mathrm{PhD}$ education. At the same time, clarity is required regarding the structure of the available supports, and early opportunities should be provided for inter disciplinary, inter sectoral, and inter national meetings to allow for the constant and integrative level of communication necessary for interdisciplinarity (Hattery 1986).

One of the benefits of an interdisciplinary approach has been identified as the creation of 'a kind of meta-knowledge' (Karlqvist 1999, 379). Seeing the value of this meta-knowledge in the PhD context can be difficult, where narrow but deep expertise is an end goal. It is interesting that our students refer to the benefit of accessing different perspectives more often than they mention access to extra-disciplinary knowledge. While both are important benefits of the interdisciplinary PhD programme, the resource most valued through the ties developed is an ability to see a challenge through a different set of eyes. This speaks to the 'new lines of flight, new directions, new inspirations, new energy or new possibilities' referred to by Martimianakis and Muzzin (2015). Our experience suggests that programme design should incorporate not only straight knowledge exchange activities, but also this ability to appreciate and exploit various perspectives to truly benefit from the social capital developed in an interdisciplinary programme.

\section{The drive to make and use interdisciplinary ties (motivating)}

There is a conundrum evident within both the literature and the student accounts as to the personal motivations that will carry a student through their PhD programme in an interdisciplinary context. As previously discussed, current structures within higher education institutions are unidisciplinary, with 
students expected to be many things to many different people and institutions - 'individual disciplinary representatives, committed team players, in addition to hardworking employees, meeting the requirements from the external funds and from the research management' (Lindvig 2018). The student must therefore draw their personal motivation from these multiple strands in order to maintain engagement with the programme. They must be proud of their own disciplinary roots, thrive in a team-based environment, gain personal satisfaction from hard work and be comfortable with the requirements of both external funders and internal management. The happiest of our interviewees were secure in the belief that this experience would pay off for them individually in terms of more or indeed better career options. They believed that the social capital they were building within the network would establish them within their career and provide long-term access benefits into the future.

Societal motivators came across more strongly than personal motivators in this research, perhaps indicating that a particular type of motivation is either more likely or more productive in an interdisciplinary environment. The desire to have an influence in the real world and change peoples' lives for the better through changing practice, changing lives, or commercialisation can perhaps help students to overcome or deal with the dual uncertainties of early stage research (doctoral studies) and interdisciplinarity. The strength of societal motivators could, of course, also be related to the fact that health is the subject of the research. Key to making an impact on real lives and the real world was the realisation of value. Value is both a key to, and one result of, the development and exploitation of social capital. A question arises as to whether participation in the programme drove need to make a difference, or this need preexisted and in fact drove programme choice That said, our data shows that engagement in this interdisciplinary PhD network strongly motivates students to look beyond their own discipline for assistance in making such an impact.

The emphasis placed by students on the level of uncertainty experienced reflects perhaps a layering of uncertainty upon uncertainty. The doctoral experience is already fraught with inherent uncertainty that can be ameliorated, as Pilbeam and colleagues (2013) pointed out, by sharing the experience with others. Interdisciplinarity may, however, hinder this sharing of experience. It adds to the existing personal challenges involved in forging respect and trust-laden relationship (Brewer 1999) and complicates both teaching and learning as methods vary from discipline to discipline (Bradbeer 1999). Language used in one discipline may be understood differently or not at all in another. Our findings reinforce the need for students to tackle such uncertainty head-on by taking the management of their career into their own hands (Martimianakis and Muzzin 2015). They must, however, be equipped and facilitated to do so through the development of uncertainty minimising strategies including an increased emphasis on team building in a managed, rather than an organic, process. Programme designers and managers should devote time to the construction of a programme scaffold that enables and empowers the team to work together.

While the summer schools organised as part of this training networks focus on student learning we suggest that interdisciplinary and intersectoral education should also be provided for supervisors, the vast majority of whom have been educated in disciplinary silos. Workshops, problem-based learning session and field work visits would all enable supervisors to build their own networks, develop a shared language with intersectoral colleagues enhancing their own social capital, while creating a better understanding for themselves of the learning students will gain during their PhD studies. In relation to the intersectoral secondments we also suggest that by scaffolding the secondment experience (e.g. identifying learning objectives, short and long-term goals, reflecting on planned and unplanned learning) students and supervisors would gain greater value.

Including students and/or recent graduates in the development and design of the education programmes going forward would allow more structured input from students. Indeed, more control for students may well remove and/or address some of the uncertainties identified thus motivating student learning to a greater degree. 


\section{Notes}

1. Under the Marie Curie-Sklowdowska Initial Training Networks funding programme, see https://ec.europa.eu/ research/mariecurieactions/

2. www.chessitn.eu

3. www.catchitn.eu

4. www.teamitn.eu

\section{Disclosure statement}

Associate Professor Tara Cusack was a co-applicant on the CHESS proposal and supervised one PhD student who participated in this study. She did not read or analyse the data from her PhD student. Dr. Threase Kessie is the Project Manager of the CATCH and CHESS Initial Training Networks.

\section{Funding}

CHESS, CATCH and TEAM have received funding from the European Union's Horizon 2020 Research and Innovation Programme under the Marie Sklodowska-Curie grant agreement nos. 676201, 722012 and 722561, respectively.

\section{ORCID}

Nicola Mountford (D) http://orcid.org/0000-0001-5485-9425

Threase Kessie (D) http://orcid.org/0000-0001-5406-9810

Tara Cusack (D) http://orcid.org/0000-0003-1887-3718

\section{References}

Arenson, C., E. Umland, L. Collins, S. B. Kern, L. A. Hewston, C. Jerpbak, R. Antony, M. Rose, and K. Lyons. 2014. "The Health Mentors Program: Three Years Experience with Longitudinal, Patient-Centered Interprofessional Education." Journal of Interprofessional Care 29 (2): 138-43.

Berger, G. 1972. "The Interdisciplinary Archipelago." In Interdisciplinarity. Problems of Teaching and Research in Universities, edited by L. Apostel, E. Jantsch, and J. Piaget, 35-74. Paris: OECD.

Blair, E. 2015. "A Reflexive Exploration of Two Qualitative Data Coding Techniques." Journal of Methods and Measurement in the Social Sciences 6 (1): 14-29.

Bourdieu, P. 1985-86. "The Forms of Capital." In Handbook of Theory and Research for the Sociology of Education, edited by J. Richardson. New York: Greenwood Press.

Boyatzis, R. E. 1998. Transforming Qualitative Information: Thematic Analysis and Code Development. London: Sage.

Bradbeer, J. 1999. "Barriers to Interdisciplinarity: Disciplinary Discourses and Student Learning." Journal of Geography in Higher Education 23 (3): 381-96.

Braddock, R., J. Fien, and R. Rickson. 1994. "Environmental Studies: Managing the Disciplinary Divide." The Environmentalist 14 (1): 35-46.

Braun, V., and V. Clarke. 2006. “Using Thematic Analysis in Psychology." Qualitative Research in Psychology 3 (2): 77-101.

Brewer, G. D. 1999. "The Challenges of Interdisciplinarity." Policy Sciences 32 (4): 327-37.

Bruhn, J. G. 2000. "Interdisciplinary Research: A Philosophy, Art Form, Artifact or Antidote?" Integrative Psychological and Behavioral Science 35 (1): 58-66.

Caulfield, B. M., and S. C. Donnelly. May, 2013. "What Is Connected Health and Why Will It Change Your Practice?" Quarterly Journal of Medicine 106 (8): 703-707.

Demharter, S., N. Pearce, K. Beattie, I. Frost, J. Leem, A. Martin, R. Oppenheimer, et al. 2017. “Ten Simple Rules for Surviving an Interdisciplinary PhD." PLOS Computational Biology 13 (5): e1005512.

Enns, S., T. Malinick, and R. Matthews. 2008. "It's Not Only Who You Know, It's Also Where They Are: Using the Position Generator to Investigate the Structure of Access to Embedded Resources." In Social Capital: An International Research Program, 255-81. Oxford: Oxford University Press.

Filieri, R., R. C. McNally, M. O'Dwyer, and L. O'Malley. 2014. "Structural Social Capital Evolution and Knowledge Transfer: Evidence from an Irish Pharmaceutical Network." Industrial Marketing Management 43 (3): 429-40.

Fry, G. L. 2001. "Multifunctional Landscapes - Towards Transdisciplinary Research." Landscape and Urban Planning 57 (34): 159-68.

Gardner, S. K. 2011. "'A Jack of All Trades and a Master of Some of Them': Successful Students in Interdisciplinary PhD Programs." Issues in Interdisciplinary Studies 29, 84-117. 
Gonzalez-Brambila, C. N. 2014. "Social Capital in Academia." Scientometrics 101 (3): 1609-25.

Gooderham, P. N. 2007. "Enhancing Knowledge Transfer in Multinational Corporations: A Dynamic Capabilities Driven Model." Knowledge Management Research \& Practice 5 (1): 34-43.

Granovetter, M. S. 1973. "The Strength of Weak Ties." The American Journal of Sociology 78 (6): 1360-80.

Hattery, L. H. 1986. "Interdisciplinary Research Management." In Interdisciplinary Analysis and Research, edited by D. E. Chubin, A. L. Porter, F. A. Rossini, and T. Connolly, 13-28. Mt. Airy, Maryland: Lomond Publications.

Ishida, T., T. Sawaragi, K. Nakakoji, and T. Sogo. 2017. "Interdisciplinary Education for Design Innovation." Computer 50 (5): 44-52.

Kadushin, C. 2012. Understanding Social Networks: Theories, Concepts, and Findings. New York: Oxford University Press.

Karlqvist, A. 1999. "Going Beyond Disciplines." Policy Sciences 32 (4): 379-83.

Klein, J. T. 1990. Interdisciplinarity: History, Theory, and Practice. Detroit: Wayne State University Press.

Krishna, A., and N. Uphoff. 2002. "Mapping and Measuring Social Capital Through Assessment of Collective Action to Conserve and Develop Watersheds in Rajasthan, India." In The Role of Social Capital in Development: An Empirical Assessment, edited by C. Grootaert and T. van Bastelaer, 85-124. Cambridge: Cambridge University Press.

Lin, N. 1999. "Social Networks and Status Attainment." Annual Review of Sociology 25 (1): 467-87.

Lin, N., and B. Erickson. 2008. Social Capital: An International Research Program. London: Oxford University Press.

Lindvig, K. 2018. "The Implied PhD Student of Interdisciplinary Research Projects Within Monodisciplinary Structures." Higher Education Research \& Development 37 (6), 1171-1185.

Luks, F., and B. Siebenhüner. 2007. "Transdisciplinarity for Social Learning? The Contribution of the German SocioEcological Research Initiative to Sustainability Governance." Ecological Economics 63 (2-3): 418-26.

Magee, M. P. 2008. "Civic Participation and Social Capital: A Social Network Analysis in Two American Counties." In Social Capital an International Research Program, edited by N. Lin and B. Erickson, 308-331. New York: Oxford University Press.

Martimianakis, M. A., and L. Muzzin. 2015. "Discourses of Interdisciplinarity and the Shifting Topography of Academic Work: Generational Perspectives on Facilitating and Resisting Neoliberalism." Studies in Higher Education 40 (8): 1454-70.

Mountford, N., I. Chouvarda, M. Isomursu, and B. Caulfield. 2017. "Vectors and Drivers of Connected Health in Europe: A Foundation for Integrated Care." International Journal of Integrated Care 17 (5): A305.

Mountford, N., E. Dorronzoro Zubiete, T. Kessie, B. Garcia-Zapirain, R. Nuño-Solinís, D. Coyle, K. B. Munksgaard, et al. 2018. "Activating Technology for Connected Health in Cancer: Protocol for a Research and Training Program." JMIR Research Protocols 7 (1): e14.

Nagy, W., and D. Townsend. 2012. "Words as Tools: Learning Academic Vocabulary as Language Acquisition." Reading Research Quarterly 47 (1): 91-108.

Nahapiet, J., and S. Ghoshal. 2000. "Social Capital, Intellectual Capital, and the Organizational Advantage." In Knowledge and Social Capital Foundations and Applications, edited by E. L. Lesser, 119-57. Boston: Butterworth Heinemann.

Pilbeam, C., G. Lloyd-Jones, and D. Denyer. 2013. "Leveraging Value in Doctoral Student Networks Through Social Capital." Studies in Higher Education 38 (10): 1472-489.

Putnam, R. 1993. "The Prosperous Community: Social Capital and Public Life." The American Prospect 13 (4, Spring). Available online: http://www.prospect.org/print/vol/13 (accessed 27 May 2019).

Seibert, S. E., M. L. Kraimer, and R. C. Liden. 2001. "A Social Capital Theory of Career Success." Academy of Management Journal 44 (2): 219-37.

Spradley, J. 2016. The Ethnographic Interview. Long Grove, IL: Waveland Press Inc.

Stozhko, N., B. Bortnik, L. Mironova, A. Tchernysheva, and E. Podshivalova. 2015. "Interdisciplinary Project-Based Learning: Technology for Improving Student Cognition." Research in Learning Technology 23: 1-13.

Uphoff, N. 2000. "Understanding Social Capital: Learning from the Analysis and Experience of Participation." In Social Capital: A Multifaceted Perspective, edited by P. Dasgupta and I. Serageldin, 215-49. Washington, DC: The World Bank. Van Noorden, R. 2015. "Interdisciplinary Research by the Numbers." Nature News 525 (7569): 306.

Wall, S., and I. Shankar. 2008. "Adventures in Transdisciplinary Learning." Studies in Higher Education 33 (5): 551-65. 